\title{
Preparation of Stable Poly(vinyl alcohol) Thin Films from Aqueous Solution on Silicon Wafer
}

Margaret Minett, Sono Sasaki\&, and Wei Chen*, Department of Chemistry, Mount Holyoke College

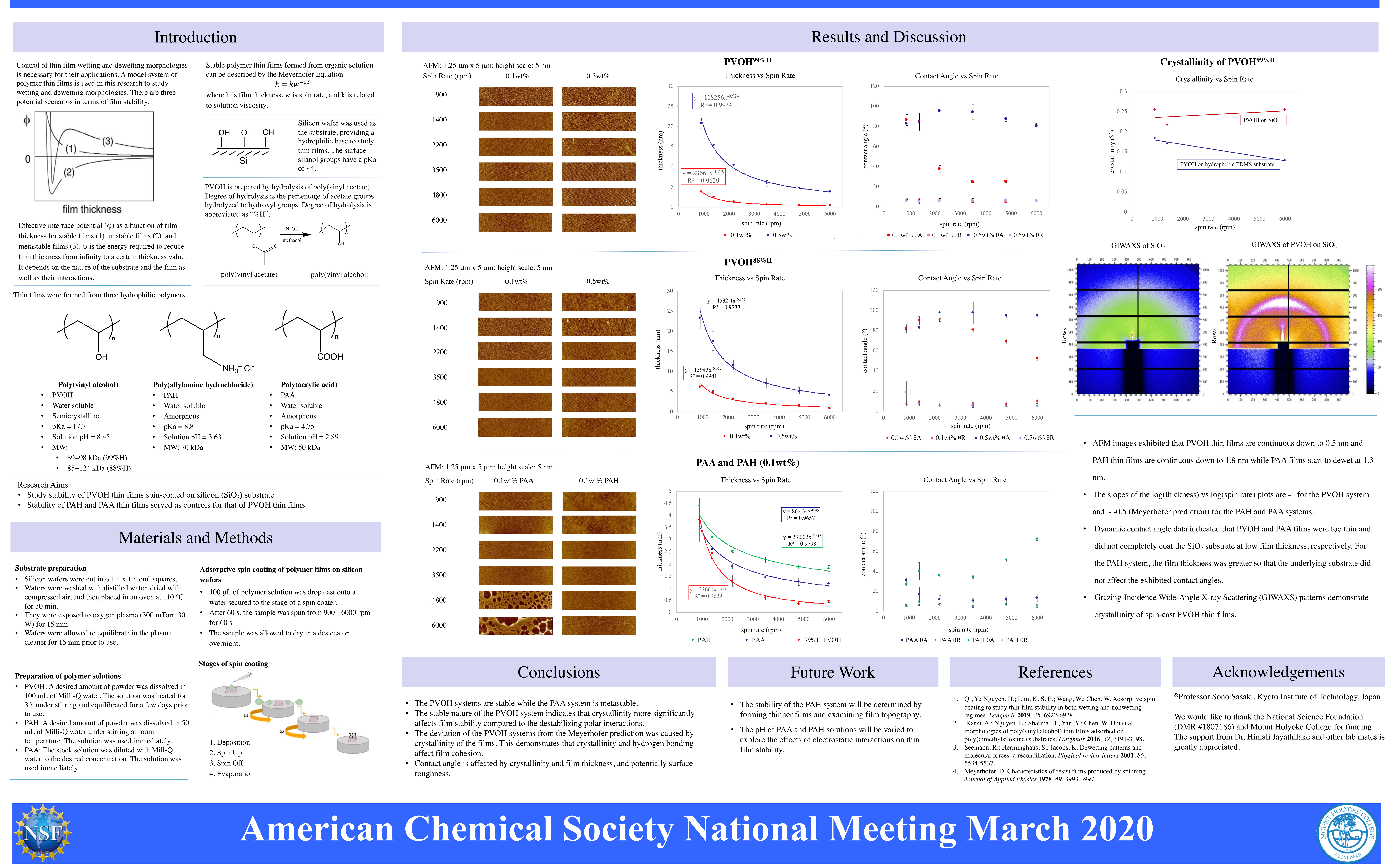

